\title{
Successful GP intervention with frequent attenders in primary care: randomised controlled trial
}

\author{
Juan Ángel Bellón, Antonina Rodríguez-Bayón, Juan de Dios Luna \\ and Francisco Torres-González
}

\begin{abstract}
Background

Frequent attenders to GP clinics can place an unnecessary burden on primary care. Interventions to reduce frequent attendance have had mixed results.

Aim

To assess the effectiveness of a GP intervention to reduce frequent-attender consultations.

Design of study

Randomised controlled trial with frequent attenders divided into an intervention group and two control groups (one control group was seen by GPs also providing care to patients undergoing the intervention). Setting

A health centre in southern Spain.

\section{Method}

Six GPs and 209 randomly-selected frequent attenders participated. Three GPs were randomly allocated to perform the new intervention: of the 137 frequent attenders registered with these three GPs, 66 were randomly allocated to receive the intervention (IG) and 71 to a usual care control group (CG2). The other three GPs offered usual care to the other 72 frequent attenders (CG1). The main outcome measure was the total number of consultations 1 year postintervention. Baseline measurements were recorded of sociodemographic characteristics, provider-user interface, chronic illnesses, and psychosocial variables. GPs allocated to the new intervention received 15 hours' training which incorporated biopsychosocial, organisational, and relational approaches. After 1 year of follow-up frequent attenders were contacted. An intention-to-treat analysis was used.

Results

A multilevel model was built with three factors: time, patient, and doctor. After adjusting for covariates, the mean number of visits at 1 year in IG was 13.10 (95\% confidence interval $[\mathrm{Cl}]=11.39$ to 14.94$)$; in the CG1 group was 19.37 (95\% Cl=17.31 to 21.55$)$; and in the CG2 group this was $16.72(95 \% \mathrm{Cl}=14.84$ to 18.72$)$.

\section{Conclusion}

The new intervention with GPs resulted in a significant and relevant reduction in frequent-attender consultations. Although further trials are needed, this intervention is recommended to GPs interested in reducing consultations by their frequent attenders. Keywords

primary health care: utilisation; randomised controlled trial.
\end{abstract}

\section{INTRODUCTION}

Patients who frequently consult their GP generate an enhanced workload for primary care, ${ }^{1}$ and the proportion of patients who frequently attend appears to be increasing. ${ }^{2}$ A systematic review indicated that frequent attenders are highly heterogeneous, and have high rates of physical disease, psychiatric illness, and social difficulty. ${ }^{3}$

One group of intervention studies with frequent attenders focused on characteristics associated with frequent attendance, such as psychosocial factors, including depression, ${ }^{4,5}$ somatisation, ${ }^{6}$ stressful experiences, ${ }^{7}$ or widowhood; ${ }^{8}$ or physical factors such as chronic bronchitis, ${ }^{9}$ or diabetes. ${ }^{10} \mathrm{~A}$ common underlying assumption is that if health problems are improved, the need to consult decreases, although findings to support this have been both negative $e^{4,5}$ and positive. ${ }^{6-10}$

Another group of intervention studies ${ }^{11-16}$ used a comprehensive focus with multi-component interventions, although results were inconclusive, and the interventions tended to be unsuccessful; also, most of these studies had methodological problems. O'Dowd intervened successfully in 'heartsink' patients, most of whom are frequent attenders, although no control group was involved. ${ }^{11}$

Matalon et al did not use a random selection of

JA Bellón, MD, GP, 'El Palo' Health Centre, and associate professor, Department of Preventive Medicine, University of Málaga; A Rodríguez-Bayón, MD, GP, San José Health Centre, Family and Community Medicine Unit of Jaén, Linares; JD Luna, PhD, professor, Department of Biostatistics, University of Granada; F Torres-González, MD, professor, Department of Psychiatry, University of Granada, Spain.

Address for correspondence

Dr Juan Angel Bellón, Facultad de Medicina, Departamento de Medicina Preventiva y Salud Pública, Campus Universitario de Teatinos 29071 Malaga, Spain.

E-mail: JABELLON@terra.es

Submitted: 4 July 2007; Editor's response: 23 September 2007; final acceptance: 18 February 2008.

(C)British Journal of General Practice 2008; 58: 324-330.

DOI: 10.3399/bjgp08X280182 
frequent attenders or control group and their intervention was not performed by the frequent attenders' GPs; the patients were referred to a specialised clinic. ${ }^{2}$

Jiwa had a control group but found no differences, possibly because the follow-up was too brief (5 months) or the intervention inappropriate. ${ }^{13}$

Christiansen et al undertook a randomised controlled trial that reduced the out-of-hours visits by frequent attenders, but with no relevant results concerning GP consultations. ${ }^{14}$

Finally, another group of mostly well-designed intervention studies focused on older patients, but again with both negative ${ }^{15}$ and positive ${ }^{16}$ results.

The present study aimed to assess the effectiveness of a new comprehensive GP intervention for decreasing consultations by frequent attenders.

\section{METHOD}

\section{Design}

A randomised controlled trial was undertaken with three arms of frequent attenders: one intervention group ( $n=66)$ and two control groups receiving usual GP care (control group 1, $n=71$; and control group 2 , who consulted the same GPs as the intervention group, $n=72$ ).

\section{Setting}

The study was undertaken at San José Health Centre in Linares (in the province of Jaén, southern Spain), a city with approximately 65000 inhabitants. This particular health centre serves a population of 15015 inhabitants from a geographically-defined area in the city; 12978 are aged 14 years or over and are attended by nine GPs. In the health centre the doctors work as a group with extensive primary care teams. The Spanish national health service provides free medical care to $100 \%$ of the population and is financed through the general national budget. Patients do not pay directly for this service; hence they have no financial constraints on consultations.

\section{Inclusion criteria and definition of frequent attender}

The sample of frequent attenders was identified with reference to mean annual consultation rates (before intervention) at the health centre, stratified by sex and age. Without such stratification, samples may be biased towards older patients and women. ${ }^{17}$ Frequent attenders were defined as those who had an annual rate of consultation at least twice as high as the sex- and age-related mean for the health centre. ${ }^{18}$ These criteria corresponded approximately to the 90th percentile of the overall distribution of consultations by frequent attenders. The cut-off annual consultation rates are shown in Table 1.

\section{How this fits in}

Comprehensive GP interventions with frequent attenders have so far failed to improve outcomes and decrease consultations. This is thought to be the first randomised controlled trial of a comprehensive GP intervention with frequent attenders that resulted in a significant and relevant reduction in their consultations.

This intervention is a possible clinical tool to reduce consultations in primary care. Although further randomised controlled trials are necessary, this new intervention is recommended to GPs who are interested in reducing their frequent attenders' consultations.

\section{Sample selection, masking, randomisation, and allocation}

Two GPs were excluded because they failed to record clinical notes accurately on their computers. The seven remaining GPs all declared their willingness to participate in the trial. Using opaque envelopes, three GPs were randomly selected to implement the intervention after training; and three other GPs were selected to provide usual care to one of the two control groups of frequent attenders (control group 1). The three GPs allocated to the intervention group were also assigned another patient group of frequent attenders from their own list who received usual care (control group 2; Appendix 1).

Randomisation and allocation to the groups was blinded by computer-generated randomisation performed by a person independent of the research team and the GPs involved. The three GPs overseeing control group 1 were blinded to the allocation of all the frequent attenders who participated in the trial. Obviously, the frequent attenders and their three GPs knew that they formed part of the intervention group, but these three GPs were blinded to the frequent attenders allocated to the two control groups. No frequent attender was aware that the study's primary outcome was the number of consultations during the follow-up, only that the aim was to improve their health.

All frequent attenders gave consent to be interviewed and to consultation of their clinical notes. Additionally, each of the three GPs allocated to the intervention group requested further consent to the

\section{Table 1. Cut-off annual consultation rates to determine frequent attendance according to age and sex.}

\begin{tabular}{lcccccc} 
& \multicolumn{3}{c}{ Females } & \multicolumn{4}{c}{ Males } \\
\cline { 2 - 7 } Age, years & $n$ & Mean visits $^{\mathrm{a}}$ & Cut-off $^{\mathrm{b}}$ & $n$ & Mean visits $^{\mathrm{a}}$ & Cut-off $^{\mathrm{b}}$ \\
\hline $15-34$ & 2234 & 4.37 & 9 & 2315 & 3.51 & 7 \\
$35-44$ & 1235 & 5.78 & 12 & 1202 & 4.65 & 9 \\
$45-64$ & 1642 & 10.71 & 21 & 1539 & 8.73 & 17 \\
$>64$ & 1584 & 14.66 & 29 & 1227 & 13.78 & 28 \\
\hline Total & 6695 & & \multicolumn{5}{c}{6283} \\
\hline
\end{tabular}

aMean total visits to San José Health Centre in the year before the intervention, stratified by age and sex. ${ }^{b}$ Double the mean total visits in the year before intervention, stratified by age and sex. 
new intervention from the patients selected for the intervention. By using a design in which patients remained unaware that two interventions were compared, an attempt was made to control for contamination between patient groups; a similar strategy has been used by Jellema et al. ${ }^{19}$

The enrolment interviews, held between January and March 2001, were undertaken by three assistant researchers blinded to the allocation groups. The frequent attenders in the intervention group were recruited to start the intervention between April and June 2001. The follow-up for all frequent attenders began on 28 June 2001 and continued for 1 year, after which the three assistant researchers attempted to contact the frequent attenders who had started the follow-up.

Sample size calculation was based on the assumption that the maximum number of frequent attenders that each GP in the intervention group was able to intervene for was $n=24$; hence the intervention group and the control groups would have 72 frequent attenders each. A pilot sample gave a standard deviation of 11 visits per frequent attender, and an intraclass correlation coefficient for GP cluster of 0.015 (with the final data it was slightly lower at 0.013 ). A reduction of five consultations was considered to be relevant from clinical and organisational perspectives. Thus, for a power of $0.80,60$ frequent attenders were needed per group without considering the design effect, and 74 frequent attenders when this was considered (design effect of 1.23).

\section{Variables}

The primary outcome measure was the total number of consultations over 1 year post-intervention. Consultations included face-to-face and home visits by GPs or nurses, and also out-of-hours visits to the health centre. Telephone calls or hospital visits were not included because reliable data were unavailable. Three assistant researchers, blinded to group allocation, obtained the primary outcome results from the computerised clinical records.

\section{Independent variables}

Independent variables were obtained in two different ways: interviewing the frequent attenders and consulting the computerised clinical records. At all times, GPs were blinded to the information obtained during the patient interviews.

\section{Sociodemographic variables}

Sociodemographic variables were categorised according to the classification of the Spanish National Institute of Statistics, ${ }^{20}$ and social class according to an adaptation of the National Classification of Occupations. ${ }^{21}$

\section{Provider-user interface variables}

Travelling time to the health centre and satisfaction with the physician were recorded. Referrals to a specialist were obtained from the computerised clinical records. It was also investigated whether the patient had used a private doctor during the previous year.

\section{Chronic disease and self-reported health}

Data concerning chronic disease were obtained from the computerised clinical records and classified according to the International Classification of Primary Care (ICPC-2), ${ }^{22}$ and from self-reported health by interview.

\section{Psychosocial variables}

These included anxiety (State-Trait Anxiety Inventory); ${ }^{23}$ depression (Beck Depression Inventory, short form, 13 items); ;4,25 hypochondria (General Hypochondria and Witheley Index from the IIIness Behaviour Questionnaire, ${ }^{26}$ which in the Spanish validation are joined in one single hypochondria factor with 19 items ${ }^{27}$ ); social support (Duke-UNC Functional Social Support Questionnaire); ${ }^{28,29}$ family dysfunction (family APGAR index); ${ }^{30,31}$ and Family Environment Scale (three dimensions: cohesion, expressiveness, and conflict). ${ }^{32}$

\section{The '7 hypothesis + team' intervention}

The three GPs in the intervention group undertook an interactive workshop training session (15 hours) on the '7 hypotheses + team' $(7 \mathrm{H}+\mathrm{T})$ intervention. In short, this intervention encourages GPs to select from a list of seven possible hypotheses for why the patient is a frequent attender: biological, psychological, social, family, cultural, administrative-organisational, or related to the doctor-patient relationship. They then share with other GPs their analyses about the hypothesis and the plans derived from it, which is the 'team' aspect of the intervention (Appendix 2).

The $7 \mathrm{H}+\mathrm{T}$ intervention has been developed over time ${ }^{11-14}$ and is based on the experience of JA Bellón since 1998. Different versions of the workshop have been given around Spain. ${ }^{33-35}$ The $7 \mathrm{H}+\mathrm{T}$ is a methodical intervention performed by a team of GPs but implemented individually. The $7 \mathrm{H}+\mathrm{T}$ intervention is performed in a step-like sequence.

The intervention workshop was given by JA Bellón over 3 days during the first week of March 2001. In addition to the workshop, five frequent attenders from the intervention group were used for pilot training. These five frequent attenders were thus excluded from the intervention group and follow-up analysis. The three GPs in control group 1 did not receive the workshop session.

Intention-to-treat analysis and imputed data An intention-to-treat analysis was carried out with all 
the frequent attenders, including those who were lost to follow-up, excluded during follow-up, or discontinued the intervention. The 'multiple imputation by chained equations' (MICE) method was used to represent the outcomes in participants whose outcome was unobserved. ${ }^{36,37}$

In these analyses, an imputation model was developed which relates the primary outcome (consultations over 1 year follow-up) to covariates with complete data using chained linear regression equations. Ten imputed datasets were used to measure uncertainty about the imputed value and, finally, standard errors of coefficients were obtained combining standard errors from 10 models and variability between the coefficients..$^{35}$

These analyses were performed using the 'ICE' command from Stata 9.2. ${ }^{38}$ Analyses were repeated for participants with complete outcome variables as a sensitivity analysis.

\section{Multilevel analysis}

The random component of the model was represented by variability at three levels: time, patient, and doctor. The outcome variable was the square root of the total number of visits during the post-intervention year. The fixed component of the adjusted model needed to include the allocation group, and a dummy time variable for baseline and post-treatment measures. The model was checked for interaction between the two variables, which was included in the model. All covariates that were significant in bivariate analysis $(P<0.30)$ were then included in the model.

All variables with a significance level versus their null hypothesis (no association with the outcome variable) greater than $30 \%$ were excluded from the model. This strategy made exclusion of relevant variables from the model unlikely. Combining coefficients of group, time, and the interaction 'group $x$ time' of this final model, the comparison between groups was analysed to test these differences adjusted for the covariates of the model, and to calculate confidence intervals for those differences using adjusted means of the annual number of visits obtained from the model. The multilevel analyses were performed using Stata 9.2, and MLwiN 2.0, with both producing similar results.

\section{RESULTS}

Of the 8652 patients aged 14 years or over registered with the six GPs selected, 880 (10.2\%) patients were classified as frequent attenders (Appendix 1). Only 229 of the 261 frequent attenders selected were actually enrolled (87.7\%). In comparing patients who were unavailable for the initial interview with those who were interviewed no significant difference was
Table 2. Type and frequency of hypotheses proposed by GPs in the intervention group; and the decision to refute the hypotheses ( $n=66$ frequent attenders).

\begin{tabular}{lcc} 
Type of hypothesis proposed & Hypothesis (\%) & Decision to refute (\%) \\
\hline Biological & $58(87.8)$ & $25(43.1)$ \\
\hline Administrative-organisational & $42(63.6)$ & $31(73.8)$ \\
\hline Psychological & $37(56.0)$ & $25(67.6)$ \\
\hline Family & $33(50.0)$ & $13(39.4)$ \\
\hline Social & $23(34.8)$ & $19(82.6)$ \\
\hline Cultural & $16(24.2)$ & $4(25.0)$ \\
\hline Doctor-patient relationship & $12(18.1)$ & $2(16.6)$ \\
\hline
\end{tabular}

aOf a possible total of seven hypotheses, the frequency, $\mathrm{n}(\%)$, of hypotheses proposed was: 1 = 5 (7.6); 2 = 14 (21.2); 3 = 18 (27.3); 4 = 11 (16.7); 5 = 6 (9.1); 6 = 8 (12.1); 7 = 4 (6.0).

found in the distribution of sex, age, number of persons per household, number and type of chronic diseases, or number of visits and referrals to specialists. In compliance with the exclusion criteria, $43(20.6 \%)$ were lost to follow-up. Appendix 1 shows the reasons for drop-out and the distribution of the drop-outs among the three groups.

At baseline, most variables had a similar distribution in the three allocation groups (Appendix 3). The distribution of chronic disease between groups was also homogeneous for most of the 17 ICPC-2 classification groups.

Table 2 shows the type and frequency of the hypotheses that the GPs in the intervention group initially proposed when evaluating their frequent attenders prior to implementing the intervention. A biological hypothesis was associated more frequently with the administrative (59\%), psychological (55\%), and family $(50 \%)$ hypotheses; while a psychological hypothesis was associated more with the biological (55\%), social (44\%), and family (43\%) hypotheses. No significant difference between the groups was found in the mean number of referrals to specialists during the post-intervention year.

Differences were found between the 166 frequent attenders who finished the follow-up and the 63 who were not allocated, lost to follow-up, or excluded during the follow-up. These 63 frequent attenders were younger, more likely to be single and working, perceived better health, had fewer chronic diseases and fewer referrals to specialists, had a lower anxiety score and were less depressive, and fewer had chronic diseases (digestive, ear, and urinary).

Appendix 4 shows that there were few differences between the results in the multilevel model without imputed cases and the model with imputed cases and the intention-to-treat analysis. At the end of the follow-up and after adjusting for covariates, the intervention group had significantly fewer visits than control group 1 and control group 2 (Table 3). 
Table 3. Frequent attenders' mean consultations by group.

\begin{tabular}{|c|c|c|c|c|c|c|}
\hline & \multicolumn{2}{|c|}{$\begin{array}{l}\text { Intervention } \\
\text { group (IG) }\end{array}$} & \multicolumn{2}{|c|}{$\begin{array}{l}\text { Control } \\
\text { group } 1 \text { (CG1) }\end{array}$} & \multicolumn{2}{|c|}{$\begin{array}{c}\text { Control } \\
\text { group } 2 \text { (CG2) }\end{array}$} \\
\hline & Mean & $95 \% \mathrm{Cl}$ & Mean & $95 \% \mathrm{Cl}$ & Mean & $95 \% \mathrm{Cl}$ \\
\hline \multicolumn{7}{|l|}{ Unadjusted means } \\
\hline Baseline & 22.51 & 19.88 to 25.14 & 21.76 & 19.56 to 23.95 & 22.28 & 19.59 to 24.56 \\
\hline 1 year & 14.84 & 12.71 to 16.97 & 24.26 & 21.35 to 27.17 & 18.48 & 15.74 to 21.22 \\
\hline \multicolumn{7}{|l|}{ Adjusted means ${ }^{a}$} \\
\hline Baseline & 21.38 & 19.24 to 23.63 & 20.61 & 18.55 to 22.79 & 20.87 & 18.84 to 23.03 \\
\hline 1 year & 12.19 & 10.47 to 14.03 & 20.67 & 18.36 to 23.11 & 16.79 & 14.79 to 18.91 \\
\hline \multicolumn{7}{|l|}{ Adjusted means ${ }^{b}$} \\
\hline Baseline & 21.38 & 19.17 to 23.71 & 20.61 & 18.48 to 22.85 & 20.87 & 18.76 to 23.10 \\
\hline \multirow[t]{2}{*}{1 year } & 13.10 & 11.39 to 14.94 & 19.37 & 17.31 to 21.55 & 16.72 & 14.84 to 18.72 \\
\hline & Texp ${ }^{c}$ & $P$-value & Zexp ${ }^{d}$ & $P$-value & Zexp & $P$-value \\
\hline IG vs CG1, 1 year & -5.08 & $<0.001$ & -6.00 & $<0.001$ & -4.63 & 0.001 \\
\hline IG vs CG2, 1 year & -2.02 & 0.046 & -3.48 & 0.001 & -2.79 & 0.006 \\
\hline IG, 0-1 year & -8.68 & $<0.001$ & -9.32 & $<0.001$ & -8.19 & $<0.001$ \\
\hline CG1, 0-1 year & 0.40 & 0.694 & 0.05 & 0.959 & -0.91 & 0.364 \\
\hline CG2, 0-1 year & -2.59 & 0.046 & -4.01 & 0.001 & -3.81 & $<0.001$ \\
\hline
\end{tabular}

${ }^{2}$ Adjusted for covariates of multilevel model. ${ }^{\mathrm{b}}$ Adjusted for covariates of multilevel model with multiple imputation data and intention-to-treat. ${ }^{\circ}$ Experimental $T$ for unadjusted means.

${ }^{\mathrm{d}}$ Experimental $Z$ adjusted for covariates of multilevel model. ${ }^{\text {eExperimental }} Z$ adjusted for covariates of multilevel model with multiple imputation data and intention-to-treat.

\section{DISCUSSION}

\section{Summary of main findings}

The $7 \mathrm{H}+\mathrm{T}$ intervention for frequent attenders which was implemented by GPs was effective at decreasing the number of consultations. This reduction was significant and relevant when compared with the two control groups and after adjusting for covariates in a multilevel model with intention-to-treat analysis. As far as the authors are aware, this is the first randomised controlled trial of a comprehensive GP intervention with frequent attenders to obtain a relevant reduction in their consultations.

\section{Strengths and limitations of the study}

Two control groups were used with the same GPs participating in the intervention group and control group 2. This design has two advantages: it enabled estimation of the outcome difference with greater precision, and it increased the efficiency of the study by using fewer GPs. Nevertheless, it can also be considered a potential problem, as GPs could carry the new intervention over to their usual care, leading to contamination bias at the GP level. In this case the direction of bias would go against the hypothesis that the $7 \mathrm{H}+\mathrm{T}$ intervention is effective. Even so, and despite this, significant differences were seen between the intervention group and control group 2 . Therefore, it can be argued that this strategy adds strength to the study's conclusions.

These GPs were trained in the $7 \mathrm{H}+\mathrm{T}$ intervention and were convinced of its worth and efficiency, so they may have found it difficult not to apply it with their other patients, even though they were blinded to these patients, as was the case for control group 2. Therefore, it can be presumed that the $7 \mathrm{H}+\mathrm{T}$ intervention has now become part of everyday practice for those GPs involved, which supports the hypothesis that the $7 \mathrm{H}+\mathrm{T}$ intervention is related to important changes in GP practice.

As the frequent-attender groups were similar at baseline, selection bias is unlikely to have influenced the study's findings. Furthermore, the use of multilevel analysis in which adjustment was made for possible effects of clustering and the exhaustive measurement of variables that contribute to explain frequent attendance, provided greater control in the analyses. Five covariates were adjusted for: age, satisfaction with GP, number of chronic diseases, anxiety, and hypochondria. If questionnaires had not been used, anxiety and hypochondria as diagnosed by the GPs would not have been controlled for. These psychosocial variables are important predictors of frequent attendance, ${ }^{39,40}$ and the capacity to detect them varies widely among GPs. ${ }^{41}$

The frequent attenders who fulfilled the exclusion criteria during follow-up were younger and healthier than those who did not fulfill them. Most of the families who attended San José Health Centre worked in the local car industry, which at that time was in crisis, thereby explaining why some participants had to leave the area in search of a new job. This could have introduced a selection bias, although an attempt was made to minimize it by including these absent workers in the final analysis, with their outcome variable estimated using multiple imputation methods.

Although there was no significant difference between groups in the number of referrals to specialists during the post-intervention year, no assessment was made of the number of repeat visits to specialists during the follow-up because that information was unavailable; therefore, this might have involved an 'off utilisation' bias. Similarly, the $7 \mathrm{H}+\mathrm{T}$ intervention encouraged the involvement of other members of the health centre team, especially nurses and social workers, although these visits were controlled for in the analyses.

Although the number of patients in the sample was sufficient for the study's objective, only six GPs were included in the study; hence the results have limited external validity. When the study was designed it was decided not to use larger samples because there was previously no evidence of successful comprehensive GP interventions with frequent attenders.

In the opinion of the intervention GPs, frequent attendance was due to many different causes (or hypotheses) in each patient. The column entitled 'Decision to refute' in Table 2 shows the difficulty 
these GPs experienced about feeling sure of the hypothesis in question. They had more problems with the social (82.6\%) and psychological hypotheses (67.6\%), which agrees with predominant biomedical opinion. ${ }^{42}$ Difficulty being convinced about the administrative-organisational hypothesis was situated second.

GPs commented that frequent attenders too often attended just to obtain prescriptions. Although this type of visit was apparently administrative, it often included biological or psychosocial components. The biological aspect generally concerned repeat visits for stable chronic patients; ${ }^{43}$ the psychosocial aspect might be related to a kind of 'entry ticket' that masked the true reason for the request for a consultation. Perhaps patients considered that seeking help for psychosocial problems would be less acceptable (both socially and by their GPs) than asking for medical prescriptions. This is very common in Spanish primary care, ${ }^{44}$ and its modification with the GP intervention may well have contributed greatly to reducing consultations by frequent attenders.

An intervention was developed with frequent attenders and its effectiveness at decreasing their consultations evaluated. However, the active components and mechanisms of this intervention need to be elucidated. Future exploratory studies of this intervention should be undertaken. Independent health variables (self-reported health, disease diagnoses, and psychosocial variables) could have been assessed at baseline and at the end of the follow-up, which would have revealed the relationship between improvement in health and psychosocial variables, and the reduction in consultations.

The GP intervention group reported a qualitative improvement in their doctor-patient relationships, although a second score in the emotional questionnaire ${ }^{34}$ at the end of the follow-up might have added more discriminatory information. GPs often find themselves in dysfunctional doctor-frequentattender relationships, ${ }^{11-34}$ although it remains unclear how this influences frequent attendance.

Perhaps alleviating GPs' anxiety, fears, or uncertainty about dealing with frequent attenders could help to reduce frequent attendance. ${ }^{45}$ One could therefore suggest that it was not the intervention itself that produced the results but rather the 'Hawthorne effect'," whereby just having the opportunity to have their concerns taken seriously and to share with others their experience of frequent attenders enabled GPs to feel more able to reduce the number of visits by their frequent attenders. The authors also believe that intervening as a team of GPs improved the efficiency of decision making in regards to frequent attenders. Colleagues were able to help with the decisions because they did not know the specific frequent attender and were therefore emotionally more neutral.

\section{Comparison with existing literature}

One study used GP groups similarly, ${ }^{11}$ and in another the focus was more cognitive than emotional. ${ }^{13}$ Future studies should explore how the effect of the intervention is modified according to whether it is done singly or in a group. The cost of the intervention in GP training (15 hours) is low, and the time spent preparing the specific intervention for each frequent attender was reasonable (5-35 minutes); nevertheless, specific studies would be required to obtain definitive conclusions about costeffectiveness.

The authors do not support interventions in specialist clinics for frequent attenders because these might be less efficient. One study in a specialist clinic encouraged frequent attendance with a schedule of visits (2-3 hours for the first visit and 10 visits of 1 hour every 2 weeks); ${ }^{14}$ this would be neither realistic nor cost-effective in primary care.

\section{Implications for clinical practice}

Results of this study confirm that intervention strategies for frequent attendance may be better targeted at health professionals than frequent attenders. Any intervention with frequent attenders should provide answers to the biomedical and psychosocial complexity surrounding patients' problems. Interventions can also highlight the degree of dissonance, both cognitive and emotional, between the patient and the GP, ${ }^{46}$ and associated organisational factors. Comprehensive tailored strategies are recommended using a simple, common analysis with seven hypotheses, made as a team but applied individually. Pending further evidence, the authors nevertheless believe that progress has been made for many GPs and their organisations.

\section{Funding body}

This study was funded by a grant from the Spanish Society of Family and Community Medicine (SEMFyC), and by the Ministerio de Sanidad y Consumo, Instituto de Salud Carlos III (ISCIII), redIAP, (RETIC RD06/0018), and Grupo SAMSERAP (RD06/001870039). The sponsors of the study had no role in study design, data collection, data analysis, data interpretation, or writing of the report. The corresponding author had full access to all the data in the study and had final responsibility for the decision to submit for publication. Trial registration ACTR number is 12607000266460

\section{Ethical approval}

The study was approved by San Agustín Hospital Ethical Committee from Linares and by the Ethics Committee of the Complejo Hospitalario de Jaén

\section{Competing interests}

The authors have stated that there are none

\section{Acknowledgements}

We are indebted to the GPs and patients who participated in this study and to lan Johnstone for English language advice. 


\section{Discuss this article}

Contribute and read comments about this article on the Discussion Forum: http://www.rcgp.org.uk/bjgp-discuss

\section{REFERENCES}

1. Neal RD, Heywood PL, Morley S, et al. Frequency of patients' consulting in general practice and workload generated by frequent attenders: comparisons between practices. Br J Gen Pract 1998; 48(426): 895-898.

2. Gill D, Dawes M, Sharpe M, Mayou R. GP frequent consulters: their prevalence, natural history, and contribution to rising workload. $\mathrm{Br} J \mathrm{Gen}$ Pract 1998; 48(437): 1856-1857.

3. Gill D, Sharpe M. Frequent consulters in general practice: a systematic review of studies of prevalence, associations and outcome. J Psychosom Res 1999; 47(2): 115-130.

4. Katon W, Von Korff M, Lin E, et al. A randomized trial of psychiatric consultation with distressed high utilizers. Gen Hosp Psychiatry 1992; 14(2): 86-89.

5. Katzelnick DI, Simon GE, Pearson SD, et al. Randomized trial of depression management program in high utilizers of medical care. Arch Fam Med 2000; 9(4): 345-351.

6. Kolk AM, Schagen S, Hanewald GJ. Multiple medically unexplained physical symptoms and health care utilization: outcome of psychological intervention and patient-related predictors of change. J Psychosom Res 2004; 57(4):379-389.

7. Gidron Y, Duncan E, Lazar A, et al. Effects of guided written disclosure of stressful experiences on clinics visits and symptoms in frequent clinic attenders. Fam Pract 2002; 19(2): 161-166.

8. Tudiver F, Pelmaul-Woods JA, Hilditch J, et al. Do widowers use the health care system differently? Does intervention make a difference? Can Fam Physician 1995; 41: 392-400.

9. Bourbeau J, Julien M, Maltais F, et al. Reduction of hospital utilization in patients with chronic obstructive pulmonary disease: a disease specific self management intervention. Arch Intern Med 2003; 163(5): 585-591.

10. Wagner EH, Sandhu N, Newton KM, et al. Effect of improved glycemic control on health care costs and utilization. JAMA 2001; 285(2): 182-189.

11. O'Dowd T. Five years of heartsink patients in general practice. BMJ 1988; 297(6647): 528-530.

12. Matalon $\mathrm{A}, \mathrm{Nahmani} \mathrm{T}$, Rabin $\mathrm{S}$, et al. A short-term intervention in multidisciplinary referral clinic for primary care frequent attenders: description of the model, patient characteristics and their use of medical resources. Fam Pract 2002; 19(3): 251-256.

13. Jiwa M. Frequent attenders in general practice: an attempt to reduce attendance. Fam Pract 2000; 17(3): 248-251.

14. Christiansen MB, Christiansen B, Mortensen JT, Olesen F. Intervention among frequent attenders of an out-of-hours service: a stratified cluster randomised controlled trial. Scand J Prim Health Care 2004; 22(3): 180-186.

15. Engelhard JB, Toseland RW, O'Donnell JC, et al. The effectiveness and efficiency of outpatient geriatric evaluation and management. J Am Geriatr Soc 1996; 44(7): 847-856.

16. Sommers LS, Marton KI, Barbaccia JC, Randolph J. Physician, nurse and social worker collaboration in primary care for chronically ill seniors. Arch Intern Med 2000; 160(12): 1825-1833.

17. Howe A, Parry G, Pickvance D, Hockley B. Defining frequent attendance: evidence for routine age and sex correction in studies from primary care settings. Br J Gen Pract 2002; 52(480): 561-562.

18. Dowrick CF, Bellón JA, Gómez MJ. GP frequent attendance in Liverpoo and Granada: the impact of depressive symptoms. Br J Gen Pract 2000; 50(454): 361-365.

19. Jellema P, Van der Windt AWM, Van der Horst HE, et al. Should treatment of (sub) acute low back pain be aimed at psychosocia prognostic factors? Cluster randomised controlled trial in general practice. BMJ 2005; 331(7508): 84

20. Ministerio de Sanidad y Consumo. Encuesta nacional de salud [National Survey of Health]. Madrid: Ministerio de Sanidad y Consumo, 1989.

21. Domingo A, Marcos J. Propuesta de un indicador de clase social basado en la ocupación [Proposal of a social class indicator based on occupation]. Gac Sanit 1989; 10: 320-326.

22. The Classification Committee of WONCA. ICPC-2, International Classification of Primary Care. 2nd edn. Oxford: Oxford University Press,

23. Spielberg CD, Gorsuch RL, Lushene RE. Cuestionario de ansiedad estadorasgo: manual $3^{a}$ edición [State-Trait Anxiety Inventory: Manual 3rd edition]. Madrid: TEA Ediciones, 1988

24. Beck AT, Rial WY, Rickels K. Short form of depression inventory (crossvalidation). Psychol Rep 1974; 34(3): 1184-1186.

25. Conde V, Esteban T, Useros E. Estudio crítico de la fiabilidad y validez de la EEC para la medida de la depresión de Beck [Critical study of reliability and validity of the Beck Inventory for measuring depression]. Arch Neurobiol (Madr) 1976; 39: 313-338.

26. Pilowsky I, Spence ND. Manual for the Illness Behaviour Questionnaire. 2nd edn. Adelaide: University of Adelaide, Department of Psychiatry, 1983.

27. Nieto J, Abad MA, García C, López C, Morales JM. Factorización del cuestionario de conducta de enfermedad IBQ de Pilowsky en población clínica española [Factorial analysis of Pilowsky's Illness Behavioural Questionnaire in a Spanish clinical population]. Anales de Psiquiatrí 1989; 5: 104-107.

28. Broadhead WE, Gehlbach SH, Degruy FV, Kaplan BH. The DUKE-UNC functional social support questionnaire: measurement of social support in family medicine patients. Med Care 1988; 26(7): 709-723.

29. Bellón JA, Delgado A, Luna JD, Lardelli P. Validez y fiabilidad del cuestionario de apoyo social funcional DUKE-UNC-11 [Validity and reliability of the functional social support questionnaire DUKE-UNC11]. Aten Primaria 1996; 18: 153-163.

30. Smilkenstein G, Ashworth C, Montano D. Validity and reliability of the family APGAR as a test of family function. J Fam Pract 1982; 15(2): 303-311.

31. Bellón JA, Delgado A, Luna JD, Lardelli P. Validez y fiabilidad del cuestionario de función familiar APGAR familiar [Validity and reliability of the family function questionnaire 'family APGAR']. Aten Primario 1996; 18: 289-296.

32. Moos RH, Moos EJ, Trickett EJ. Escalas de clima social (FES, WES, CIES, CES) [Social Climate Scales (FES, WES, CIES, CES)]. Madrid: TEA ediciones, 1995

33. Bellón JA. Cómo reducir la utilización de las consultas de atención primaria y no morir en el intento: (I) estrategias con el usuario [How to reduce frequent attendance in primary care and not die in the attempt: (I) Strategies for users]. Sesiones clínicas c@p 1998.http://www.capsemfyc.com (accessed 8 Apr 2008).

34. Bellón JA, Fernández-Asensio MA. Emotional profile of physicians who interview frequent attenders. Patient Educ Couns 2002; 48(1): 33-41.

35. Casajuana J, Bellón JA. La gestión de la consulta en atención primaria. In: Martín-Zurro A, Cano-Pérez JF (eds). Atención primaria: conceptos, organización y práctica clínica [Primary care: concepts, organization and clinical practice]. 5th edn. Madrid: Elsevier España SA, 2003; 84-109.

36. Little RJA, Rubin DB. Statistical analysis with missing data. 2nd edn. New York: Wiley, 2002.

37. Schafer J. Analysis of incomplete multivariate data. London: Chapman and Hall, 1997.

38. Royston P. Multiple imputation of missing values: update of ice. Stata Journal 2005; 5: 527-536.

39. Bellón JA, Delgado A, Luna JD, Lardelli. Psychosocial and health belief variables associated with frequent attendance in primary care. Psychol Med 1999; 29(6): 1347-1357.

40. Bellón JA, Delgado A, Luna JD, Lardelli P. Patient psychosocial factors and primary care consultation: a cohort study. Fam Pract 2007; 24(6): $562-569$

41. Robinson JW, Roter DL. Counselling by primary care physicians of patients who disclose psychosocial problems. J Fam Pract 1999; 48(9): 698-705.

42. Dowrick C, May C, Richardson M, Bundred P. The biopsychosocial model of general practice: rhetoric or reality? Br J Gen Pract 1996; 46(403): 105-107.

43. Birtwhistle RV, Godwin MS, Delva MD, et al. Randomised equivalence trial comparing three and six months of follow up of patients with hypertension by family practitioners. BMJ 2004; 328(7433): 204-206.

44. Orozco D, Pedrera V, Gil V, et al. Gestión clínica de la consulta: previsibilidad y contenido clínico (estudio SyN-PC) [Clinical management of consultations: clinical content and predictability (SyN-PC Study)]. Aten Primaria 2004; 33: 69-77.

45. Mas-Garriga X, Cruz-Doménech JM, Fañanás-Lanau N, et al. Difficult patients in primary care: a quantitative and qualitative study. Aten Primaria 2003; 31: 214-219.

46. Smucker DR, Zink T, Susman JL, Crabtree BF. A framework for understanding visits by frequent attenders in family practice. J Fam Pract 2001; 50(10): 847-852. 


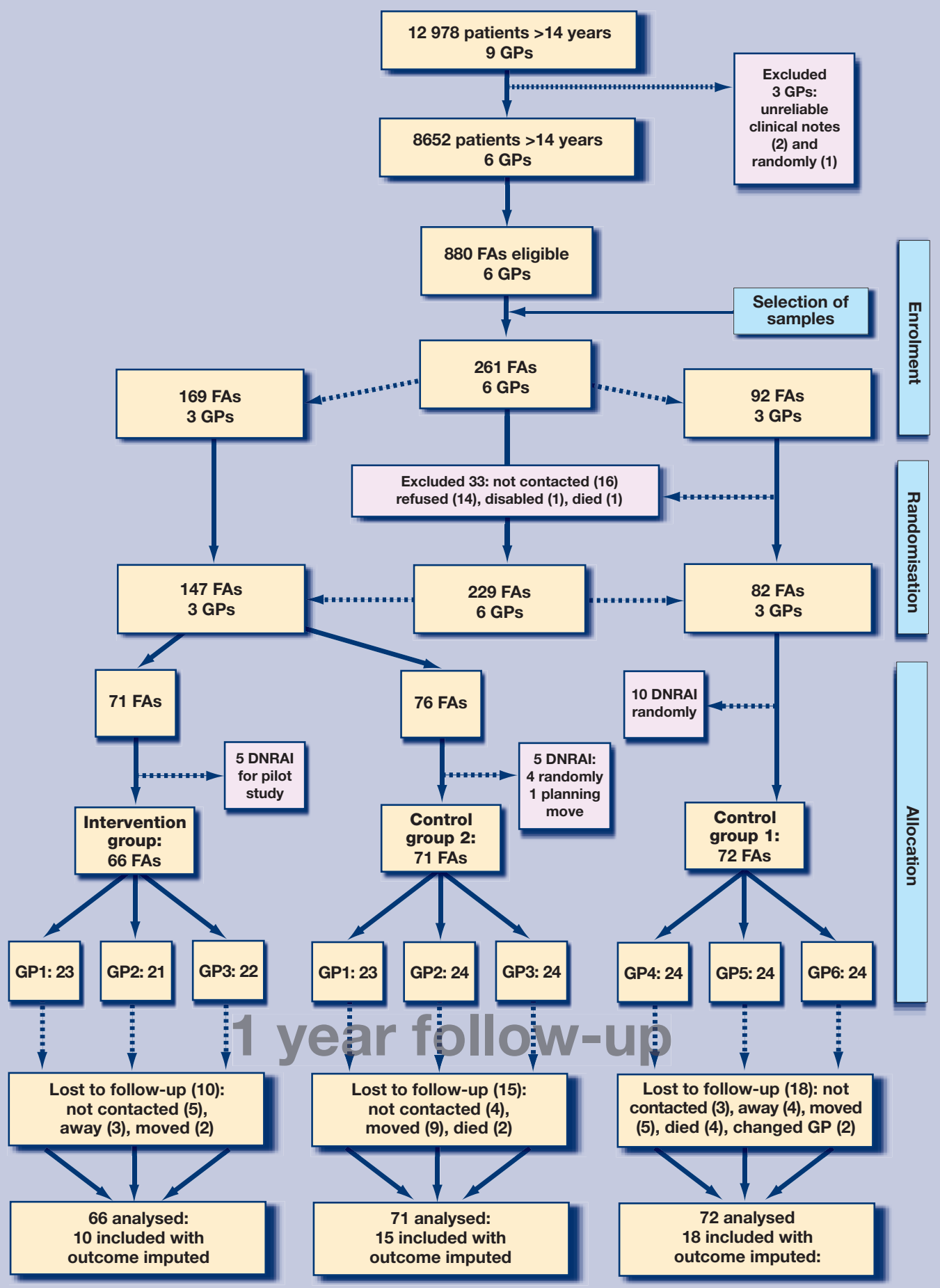

$D N R A I=$ did not receive allocated intervention. $F A=$ frequent attender.

Appendix 1. Flowchart of participants in study. 


\section{Appendix 2. The ' 7 hypothesis + team' intervention.}

Hypothesis generation: analysis of available information

GPs analyse all the available information about possible reasons for frequent attendance from clinical charts using a standardised questionnaire designed to facilitate analysis of this information. ${ }^{32-34}$

This questionnaire prompts analysis of the following: (1) category of visits and their frequencies; (2) type of frequent attender according to the first point; (3) family and personal history, and biopsychosocial problem list that needed follow-up; (4) searching for common factors for frequent attendance from the previous points; (5) feelings and thoughts questionnaires, 'In most interviews with this patient I think ...' (11 items), 'I feel ...' (13 items) ${ }^{34}$; (6) rethinking issues of GP capacity (and processes) to resolve the frequent attendance in this patient; and (7) analysing the different professionals who intervened in patient care and their contribution to resolving or continuing frequent attendance.

Finally, GPs indicate the type of hypothesis from a list of seven that they believe made the patient a frequent attender: biological, psychological, social, family, cultural, administrative-organisational, or related to the doctor-patient relationship.

Hypothesis confirmation

The decision to accept or refute each hypothesis is based on the GP's interpretation of the data (cognitive component) and the self-perception about feeling sure (emotional component). When necessary, the GPs can try out the hypothesis with one or more of the following strategies: another interview with the patient, biological and psychosocial tests, and/or asking for the opinion of other professionals.

Planning

The GP makes plans for each frequent attender based on the confirmed hypothesis and available resources. There are many possible plans, examples of which include: making longer intervals between medical revisits for stable chronic patients, and asking for collaboration with nurses; looking for possible causes of the unstable physical chronic illness and intervening accordingly; scheduling an interview to search for a psychological, family or/and, social diagnosis; suppressing unnecessary face-to-face medical revisits for repeat prescriptions in stable chronic patients, and asking the health centre administrative staff for collaboration; asking the social worker at the health centre for help; referring to community resources if necessary; and being more realistic about the type of doctor-patient relationship expected.

These plans are then commented on at the group meeting, after which the GP negotiates the plan with the frequent attender. The GP should never suggest to the patient: 'You have to attend less frequently'. This would be too aggressive and the patient might react with anger or guilt. It is better to offer a search for solutions to the patient's health problem from both points of view.

Team

GPs hold meetings to share analyses and reflections on their frequent attenders and make plans for each frequent attender. Moreover, the GP team provides emotional support to each GP and generates strategies to deal with frequent attenders from a more neutral perspective. The time spent sharing each reflection about a frequent attender ranges from 5 to 35 minutes. The GP team sets regular meetings to discuss (and possibly coming to a consensus agreement about) the hypotheses and plans for all the patients included in the intervention group.

More detailed information on the $7 H+T$ intervention can be obtained from the corresponding author. 


\section{Appendix 3. Baseline comparisons between groups and independent variables.}

\begin{tabular}{|c|c|c|c|c|c|c|}
\hline Variables & Inter & $\begin{array}{l}\text { vention group } \\
\qquad n=71\end{array}$ & \multicolumn{2}{|c|}{$\begin{array}{c}\text { Control group } 1 \\
n=82\end{array}$} & \multicolumn{2}{|c|}{$\begin{array}{c}\text { Control group } 2 \\
n=76\end{array}$} \\
\hline Sex (female), $n$ (\%) & & $39(54.9)$ & \multicolumn{2}{|c|}{$44(53.7)$} & \multicolumn{2}{|c|}{39 (51.3) } \\
\hline $\begin{array}{l}\text { Level of education } \\
\text { ( } \geq \text { secondary school), } n(\%)\end{array}$ & & $20(28.2)$ & \multicolumn{2}{|c|}{$25(30.9)$} & \multicolumn{2}{|c|}{$18(23.7)$} \\
\hline $\begin{array}{l}\text { Social class: highest (I), } \\
\text { high (II), and middle level (III), } n \text { (\%) }\end{array}$ & & $15(21.1)$ & \multicolumn{2}{|c|}{$36(46.3)$} & \multicolumn{2}{|c|}{$15(20.3)$} \\
\hline Marital status (married), $n$ (\%) & & $50(70.4)$ & \multicolumn{2}{|c|}{$66(80.5)$} & \multicolumn{2}{|c|}{$54(71.1)$} \\
\hline Employment status (employed), $n$ (\%) & & $16(22.5)$ & \multicolumn{2}{|c|}{$23(28.0)$} & \multicolumn{2}{|c|}{$15(19.7)$} \\
\hline $\begin{array}{l}\text { Travelling time to health } \\
\text { centre (>20 min), } n(\%)\end{array}$ & & $9(12.7)$ & \multicolumn{2}{|c|}{$9(11.0)$} & \multicolumn{2}{|c|}{$8(10.5)$} \\
\hline $\begin{array}{l}\text { Satisfaction with GP (never, } \\
\text { almost never, sometimes), } n(\%)\end{array}$ & & $13(18.3)$ & \multicolumn{2}{|c|}{25 (31.6) } & \multicolumn{2}{|c|}{$15(19.7)$} \\
\hline $\begin{array}{l}\text { Self-reported health } \\
\text { (excellent, good), } n(\%)\end{array}$ & & $26(36.6)$ & \multicolumn{2}{|c|}{$28(35.5)$} & \multicolumn{2}{|c|}{$28(36.8)$} \\
\hline Visit to private doctor, $n(\%)$ & & $28(39.4)$ & \multicolumn{2}{|c|}{$35(43.2)$} & \multicolumn{2}{|c|}{$20(26.3)$} \\
\hline $\begin{array}{l}\text { Family dysfunction } \\
\text { (APGAR }<7), n(\%)\end{array}$ & & $10(14.1)$ & \multicolumn{2}{|c|}{$11(14.5)$} & \multicolumn{2}{|c|}{$16(21.1)$} \\
\hline $\begin{array}{l}\text { Depressive symptoms } \\
\text { (BDI positive), } n(\%)\end{array}$ & & $31(43.7)$ & & (38.2) & & $(52.6)$ \\
\hline \multirow[t]{2}{*}{ Age, years } & Mean & $95 \% \mathrm{Cl}$ & Mean & $95 \% \mathrm{Cl}$ & Mean & $95 \% \mathrm{Cl}$ \\
\hline & 47.8 & 43.5 to 52.1 & 49.1 & 45.3 to 52.9 & 51.3 & 46.9 to 55.7 \\
\hline $\begin{array}{l}\text { Number of persons } \\
\text { per household }\end{array}$ & 3.60 & 3.23 to 3.97 & 3.59 & 3.30 to 3.70 & 3.30 & 3.01 to 3.59 \\
\hline Trait anxiety (STAI-T) & 25.2 & 22.0 to 28.5 & 23.2 & 21.0 to 25.3 & 24.7 & 22.0 to 27.4 \\
\hline Depression (BDI) & 6.10 & 4.40 to 7.80 & 4.7 & 3.62 to 5.80 & 5.7 & 4.43 to 6.89 \\
\hline Hypochondria $(\mathrm{GH}+\mathrm{WI})$ & 7.39 & 6.27 to 8.51 & 6.28 & 5.39 to 7.17 & 6.47 & 5.62 to 7.32 \\
\hline $\begin{array}{l}\text { Social support } \\
\text { (Duke-UNC-11) }\end{array}$ & 25.3 & 23.1 to 27.5 & 25.4 & 23.5 to 27.2 & 22.9 & 20.9 to 24.9 \\
\hline Family cohesion (FES-Ch) & 7.12 & 6.59 to 7.64 & 7.32 & 6.88 to 7.55 & 7.04 & 6.56 to 7.52 \\
\hline Family expressivity (FES-E) & 5.70 & 5.26 to 6.13 & 5.89 & 5.56 to 6.23 & 5.97 & 5.61 to 6.34 \\
\hline Family conflict (FES-Cf) & 1.84 & 1.44 to 2.24 & 2.17 & 1.79 to 2.55 & 2.13 & 1.79 to 2.48 \\
\hline $\begin{array}{r}\text { Number of chronic } \\
\text { disease problems }\end{array}$ & 4.81 & 4.25 to 5.38 & 3.21 & 2.72 to 3.70 & 4.63 & 3.98 to 5.28 \\
\hline $\begin{array}{l}\text { Number of referrals } \\
\text { to specialists }\end{array}$ & 1.01 & 0.83 to 1.20 & 0.59 & 0.39 to 0.78 & 0.89 & 0.62 to 1.17 \\
\hline
\end{tabular}

$B D I=$ Beck Depression Inventory, short form: ${ }^{24,25}$ '(BDI positive)' refers to the dichotomised variable (depression positive versus depression negative) and 'Depression (BDI)' is the quantitative variable. STAI = State-Trait Anxiety Inventory. ${ }^{23}$

$\mathrm{GH}+\mathrm{WI}=$ General Hypochondria and Witheley Index from the IIIness Behaviour Questionnaire. ${ }^{26}$

Duke-UNC-11 = Duke University and University of North Carolina Functional Social Support Questionnaire. ${ }^{28,29}$

FES = Family Environment Scale, dimensions: ${ }^{32}$ (Ch = cohesion), $(E=$ expressiveness), $(C f=$ conflict $)$. 


\begin{tabular}{|c|c|c|c|c|c|c|}
\hline Multilevel model & \multicolumn{3}{|c|}{ Model $1(n=166)$} & \multicolumn{3}{|c|}{ Model $2(n=209)$} \\
\hline Variables & Beta & SE (beta) & $P$-value & Beta & SE (beta) & $P$-value \\
\hline Time $^{\mathrm{a}}$ & -1.0625 & 0.1015 & $<0.001$ & -0.9814 & 0.1394 & $<0.001$ \\
\hline Group $A^{b}$ & -0.4511 & 0.1746 & 0.010 & -0.1377 & 0.1459 & 0.345 \\
\hline Group Bc & -0.1185 & 0.2542 & 0.641 & -0.0072 & 0.1802 & 0.968 \\
\hline Interaction between time and group $\mathrm{A}$ & 0.9788 & 0.1421 & $<0.001$ & 0.5210 & 0.1776 & 0.003 \\
\hline Interaction between time and group $B$ & 1.3421 & 0.1464 & $<0.001$ & 0.8708 & 0.1916 & $<0.001$ \\
\hline Age & 0.0308 & 0.0047 & $<0.001$ & 0.0375 & 0.0037 & $<0.001$ \\
\hline Trait anxiety (STAI-T) & 0.0059 & 0.0068 & 0.386 & 0.0078 & 0.0055 & 0.158 \\
\hline Satisfaction with GP (group A) & -0.2353 & 0.1817 & 0.195 & -0.1260 & 0.1458 & 0.388 \\
\hline Satisfaction with GP (group B) & 0.0004 & 0.1788 & 0.998 & 0.0277 & 0.1474 & 0.851 \\
\hline Logarithm of number of chronic diseases & 0.4615 & 0.1543 & 0.003 & 0.2890 & 0.1250 & 0.021 \\
\hline Hypochondria $(\mathrm{GH}+\mathrm{WI})$ & 0.0439 & 0.0207 & 0.034 & 0.0205 & 0.0156 & 0.190 \\
\hline \multicolumn{7}{|l|}{ Random-effects parameters } \\
\hline Doctor & 0.2060 & 0.0999 & & 0.1055 & 0.0874 & \\
\hline Patient & 0.7235 & 0.0531 & & 0.5150 & 0.0644 & \\
\hline Residual & 0.5275 & 0.0295 & & 0.6875 & 0.0422 & \\
\hline
\end{tabular}

${ }^{\mathrm{a}}$ Time $=$ observation time (baseline and 1 year post-intervention). ${ }^{\mathrm{b}} \mathrm{Group} A=$ contrast between intervention group and control group 1. 'Group $B=$ contrast between intervention group and control group 2. SE: standard error. STAI = State-Trait Anxiety Inventory. ${ }^{23} \mathrm{GH}+W \mathrm{I}=$ General Hypochondria and Witheley Index from the IIIness Behaviour Questionnaire. ${ }^{26}$ 